\title{
Le cloître de l'ancien prieuré Notre-Dame de La Charité-sur-Loire (Nièvre)
}

\section{Fabrice Henrion}

\section{Q OpenEdition}

1 Journals

\section{Édition électronique}

URL : https://journals.openedition.org/cem/11892

DOI : $10.4000 /$ cem. 11892

ISSN : 1954-3093

Éditeur

Centre d'études médiévales Saint-Germain d'Auxerre

\section{Édition imprimée}

Pagination : 49

ISSN : 1623-5770

\section{Référence électronique}

Fabrice Henrion, «Le cloître de l'ancien prieuré Notre-Dame de La Charité-sur-Loire (Nièvre) », Bulletin du centre d'études médiévales d'Auxerre | BUCEMA [En ligne], 15 | 2011, mis en ligne le 22 août 2011, consulté le 22 septembre 2022. URL : http://journals.openedition.org/cem/11892 ; DOI : https:// doi.org/10.4000/cem.11892

Ce document a été généré automatiquement le 22 septembre 2022.

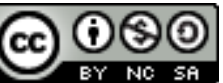

Creative Commons - Attribution - Pas d'Utilisation Commerciale - Partage dans les Mêmes Conditions 4.0 International - CC BY-NC-SA 4.0

https://creativecommons.org/licenses/by-nc-sa/4.0/ 


\title{
Le cloître de l'ancien prieuré Notre- Dame de La Charité-sur-Loire (Nièvre)
}

\author{
Fabrice Henrion
}

1 La fondation du prieuré de La Charité dans la seconde moitié du XI ${ }^{e}$ siècle participe de la volonté de Cluny d'assurer son expansion vers le nord. L'ampleur de la construction réalisée et l'organisation de son plan constituent des références, tant pour l'histoire de l'art que pour l'archéologie des monastères bénédictins, souvent réduits (après maintes destructions) à la seule église abbatiale, comme c'est le cas à Vézelay (Yonne) ou à Gigny-sur-Suran (Jura), par exemple. Les différentes campagnes archéologiques, qui se sont succédé depuis les années 1970, et plus particulièrement celles menées sous la direction de Chantal Arnaud, ont montré l'attachement des constructeurs charitois au modèle clunisien. Mais on connaît très mal l'organisation des bâtiments entre la fondation et le grand incendie de 1559 - à l'exception de l'aile est qui conserve ses dispositions gothiques -, puis les reconstructions radicales du cloître dans les années 1770.

2 Dans le cadre des travaux de restauration en cours et projetés (MH), une première intervention archéologique a été menée dans le cloître. Des sondages au sol ont été ouverts, afin de savoir si les galeries ouest et sud du cloître du XVIII siècle ont été réellement bâties ou sont seulement restées à l'état de projet, illustré par les textes d'archives. Seules les galeries nord et est sont aujourd'hui encore en élévation. Par ailleurs, la récente acquisition par la ville de La Charité des parcelles situées immédiatement à l'ouest de la cour du cloître, a rendu possible l'accès aisé à cette partie du site et à l'étude des élévations.

3 Cette étude, tant au sol qu'en élévation, a permis d'assurer que les quatre galeries du cloître ont bien été reconstruites entre 1774 et 1778 et de montrer la préservation d'élévations romanes, à l'emplacement de l'aile ouest, là où peut se trouver le cellier. Cette reconnaissance des dispositions médiévales, entre l'est et l'ouest, implique que le cloître médiéval a la même superficie que le cloître moderne (près de $2000 \mathrm{~m}^{2}$ ) et qu'il 
est sans doute organisé en terrasses, comme le suggère l'important dénivelé (3 m) entre les sols de l'aile est - en particulier de la salle capitulaire du xiII ${ }^{e}$ siècle- et ceux restitués de l'aile ouest.

4 L'étude du site doit se poursuivre en 2011, dans le cadre d'une opération programmée, en abordant, notamment, les questions liées à la chronologie des constructions de l'aile est, ainsi que de son articulation avec l'église au sud et la cour du prieuré au nord. Le programme se développera ensuite autour de l'ensemble des bâtiments monastiques et de leurs abords.

INDEX

Mots-clés : cloître, prieuré

Index géographique : France/La Charité-sur-Loire 